\title{
Keragaman Pertumbuhan dan Produksi Beberapa Aksesi Jarak Pagar (Jatropha curcas L.) di Daerah Pesisir Pantai
}

\author{
The Growth and Production of Physic Nut (Jatropha curcas L.) Accesions in Coastal Area
}

\author{
Ali Ahkamulloh, Endang Murniati, Memen Surahman* \\ Departemen Agronomi dan Hortikultura, Fakultas Pertanian, Institut Pertanian Bogor \\ (Bogor Agricultural University), Jl. Meranti, Kampus IPB Darmaga, Bogor 16680, Indonesia \\ Telp.\&Faks.62-251-8629353 e-mail agronipb@indo.net.id
}

\begin{abstract}
The aim of this research was to know the growth various accesions of physic nut in coastal area.This research was conducted from March until October 2011 at Wonokerto Kulon coastal area, Pekalongan. The evaluated accesion were derived from 14 selected parent plants originated from Central Java, South Sulawesi, West Java and West Nusa Tenggara. The accesions were selected based on provenance trials in the previous research. The seeds were germinated in the seed nursery. The seedlings were planted in to the field (8 WAP). This research was arranged in randomized complete block design. The result of this research showed that Bogor 8011-5 and IP-2P 110-1-4 are the best accesion. Bontomaramu 1-1, Medan and Pinrang. Sukabumi, Bengkulu 3, Gunung Tambora, Lombok 59-1-2, Aceh Besar, Bima, Bone, Dompu and Luwu Utara are not good to be planted in coastal area.
\end{abstract}

Keywords: accesion, physic nut, coastal area

\section{ABSTRAK}

Penelitian ini bertujuan untuk mengetahui pertumbuhan berbagai aksesi jarak pagar di daerah pesisir pantai. Penelitian ini dilaksanakan dari bulan Maret sampai Oktober 2011 di Wonokerto, pesisir Kulon, Pekalongan. Aksesi yang dievaluasi berasal dari 14 tanaman tetua yang diseleksi dari tempat asalnya Jawa Tengah, Sulawesi Selatan, Jawa Barat dan Nusa Tenggara Barat. Aksesi tersebut dipilih berdasarkan percobaan di tempat asalnya dalam penelitian sebelumnya. Benih dikecambahkan dalam pembibitan benih. Bibit ditanam ke lapangan (8 MST). Penelitian ini menggunakan Rancangan Kelompok Lengkap Teracak (RKLT) Hasil penelitian ini menunjukkan bahwa Bogor 80-11-5 dan IP-2P 110-1-4 adalah aksesi terbaik. Bontomaramu 1-1, Medan, dan Pinrang. Sukabumi, Bengkulu 3, Gunung Tambora, Lombok 59-1-2, Aceh Besar, Bima, Bone, Luwu Utara dan Dompu tidak baik untuk ditanam di daerah pesisir pantai.

Kata kunci: aksesi, jarak pagar, wilayah pesisir

\section{PENDAHULUAN}

Berdasarkan data Badan Pusat Statistik (2010), jumlah penduduk Indonesia mengalami peningkatan, dari 206,264,595 jiwa pada tahun 2000 menjadi 237,556,363 jiwa pada tahun 2010. Peningkatan tersebut berimplikasi terhadap kebutuhan sarana transportasi. Hal ini dapat menyebabkan laju konsumsi

\footnotetext{
* Penulis untuk korespondensi. e-mail: memensurahman@yahoo. com
}

bahan bakar minyak (BBM) dalam negeri semakin besar, mengingat Indonesia masih tergantung pada minyak dan sulitnya ditemukan ladang minyak baru, sehingga persediaan minyak bumi Indonesia semakin menipis. Menurut Hambali et al. (2007), Indonesia yang semula adalah net-exporter di bidang BBM kini telah berubah menjadi net-importer BBM sejak tahun 2000. Upaya untuk mengurangi permasalahan tersebut, maka dibutuhkan bahan bakar alternatif yang strategis sebagai sumber energi baru. 
Menurut Daryanto (2010), sumber energi baru tersebut bahan bakunya harus berlimpah (tersedia secara menyebar), dapat diproduksi dan dikonsumsi secara ekonomis, bersifat ramah lingkungan (harus menghasilkan emisi serendah mungkin), tersedia secara lokal, mudah diperoleh dan dapat diperbarui. Salah satu sumber energi alternatif terbarukan adalah biodiesel yang bahan bakunya dari minyak nabati.

Komoditas perkebunan penghasil minyak nabati di Indonesia yang dapat digunakan sebagai bahan baku biodiesel yaitu: minyak kelapa sawit, kelapa dan jarak pagar. Peluang pemanfaatan minyak jarak pagar untuk bahan baku biodiesel lebih besar, karena minyak jarak pagar bukan untuk konsumsi pangan, sehingga pemanfaatannya tidak akan mengganggu penyediaan kebutuhan minyak pangan nasional (Hambali et al., 2006). Jarak pagar adalah tanaman yang mampu beradaptasi dengan baik pada lingkungan yang kritis dibandingkan dengan tanaman penghasil minyak nabati lainnya. Menurut Ferry et al. (2007), jarak pagar dapat tumbuh hampir di seluruh wilayah Indonesia, termasuk daerah marginal.

Produksi jarak pagar di Indonesia ke depan diperkirakan akan menghadapi tantangan yang semakin kompleks berupa penurunan areal tanam dan penyusutan lahan subur akibat konversi lahan dari sektor pertanian menjadi sektor non pertanian. Lahan penanaman jarak pagar dalam negeri berpeluang lebih diarahkan ke lahan suboptimal, salah satunya adalah lahan di daerah pesisir pantai. Potensi lahan tersebut di Indonesia sangat tinggi, karena Indonesia merupakan negara kepulauan yang memiliki pantai sepanjang $81,000 \mathrm{~km}$ (Rahmawaty, 2006). Pengembangan jarak pagar di daerah pesisir pantai pada intinya adalah untuk memenuhi kebutuhan bahan bakar minyak diesel bagi penduduk setempat sebagai upaya mewujudkan Desa Mandiri Energi (Hamdi, 2007), penahan erosi (Hambali et al., 2006), penyerap karbon dan menurunkan suhu permukaan bumi (minimal di areal pertanaman) serta dapat meningkatkan kadar $\mathrm{O}_{2}$ dan menurunkan $\mathrm{CO}_{2}$ di udara sehingga bisa mengurangi efek pemanasan global (Parwata et al., 2010).

Menurut Triyogo et al. (2009) lahan daerah persisir pantai memiliki kelemahan berupa kandungan hara rendah, evaporasi tinggi, kandungan air tanah yang rendah, serta aliran permukaan yang terlalu besar pada musim penghujan sehingga dapat mengakibatkan hilangnya sebagian unsur hara yang terdapat di dalam tanah dan mengganggu pertumbuhan tanaman. Menurut Satyarini (2009) lahan daerah pesisir pantai selalu bersentuhan dengan udara laut yang mengandung garam dan berangin cukup besar, sehingga dianggap tidak cocok untuk usaha di bidang pertanian.

Upaya untuk memanfaatkan lahan daerah pesisir pantai adalah dengan menanam aksesi jarak pagar yang adaptif, sehingga pada penelitian ini akan dilakukan penapisan beberapa aksesi jarak pagar untuk daerah pesisir pantai agar dapat diketahui aksesi terbaik yang bisa tumbuh dan berproduksi dengan baik.

Penelitian ini bertujuan untuk mengetahui pertumbuhan empat belas aksesi jarak pagar di daerah pesisir pantai.

\section{BAHAN DAN METODE}

Penelitian ini telah dilaksanakan mulai bulan Maret sampai dengan Oktober 2011 di daerah pesisir pantai Kelurahan Wonokerto Kulon Kecamatan Wonokerto Kabupaten Pekalongan, Provinsi Jawa Tengah. Lahan penelitian sebelumnya digunakan untuk pertanaman melati, berada 1 meter di atas permukaan laut dengan jenis tanah pasir dan berjarak $\pm 54 \mathrm{~m}$ dari garis pantai.

Bahan yang digunakan adalah benih 14 aksesi jarak pagar hasil eksplorasi oleh Surfactant Bioenergy Research Center (SBRC) IPB, diantaranya adalah: Aceh Besar (Aceh), Bengkulu 3 (Bengkulu), (Bogor 80-11-5, IP-2P 110-1-4 dan Sukabumi (Jawa Barat)), (Bima, Dompu, Gunung Tambora dan Lombok 59-1-2 (Nusa Tenggara Barat)), (Bone, Bontomaramu 1-1, Luwu Utara serta Pinrang (Sulawesi Selatan)) dan Medan (Sumatera Utara). Penanaman aksesi di lapangan dilakukan dalam rancangan kelompok lengkap teracak (RKLT).

Pupuk yang digunakan adalah SP-36, $\mathrm{KCl}$ dan Urea dengan dosis masing-masing sebanyak 50, 10, 20 $\mathrm{g}$ tanaman $^{-1}$. Bahan lain yang digunakan yaitu Furadan 3G, Agrept 20WP, dan Roundup 486SL.

Penelitian dimulai dengan pengambilan sampel tanah pra dan pasca penelitian dengan bor biopori secara komposit pada kedalaman 20, 40 dan $60 \mathrm{~cm}$, kemudian sampel tanah dianalisis di Instalasi Laboratorium Kimia, Balai Penelitian Tanah, Badan Penelitian dan Pengembangan Pertanian, Departemen Pertanian, Bogor.

Pembibitan jarak pagar dilakukan selama \pm 2 bulan dengan penanaman benih di media polybag yang terdiri atas campuran tanah dan pupuk kandang siap pakai perbandingan 1:1 (v/v) (Hariyadi, 2005). Penanaman benih dilakukan dengan posisi mikropil benih menghadap ke bawah pada kedalaman $\pm 2 \mathrm{~cm}$ (Santosa dan Purwoko, 2008) di tempat terbuka yang terhindar dari naungan.

Sebelum diolah, lahan terlebih dahulu 
dibersihkan dari semak belukar kemudian dilakukan pengolahan tanah secara mekanis dengan cangkul, parang, dan garpu pendongkel. Dilakukan juga pembuatan jarak tanam dan lubang tanam 30 x 30 x $25 \mathrm{~cm}$. Jarak tanam dalam barisan $2 \mathrm{~m}$ dan antar aksesi $1 \mathrm{~m}$. Bibit jarak pagar yang berumur \pm 2 bulan ditanam di lapang sesuai dengan jarak tanam yang telah ditentukan. Tanah di sekitar batang tanaman dipadatkan dan dibuat agak cembung pada saat penanaman, sehingga tegakan tanaman kuat. Pemeliharaan tanaman di lapang dilakukan dengan memupuk, menyiram, membumbun, serta mengendalian gulma, hama dan penyakit.

Pemupukan dilakukan dengan cara memberi pupuk SP-36 dan KCL pada lubang tanam dengan dosis masing-masing sebanyak 50 dan $10 \mathrm{~g}$ tanaman $^{-1}$. pada saat jarak pagar ditanam di lapang. Setelah tanaman berusia 1 bulan di lapang, dilakukan pemupukan Urea dengan dosis $10 \mathrm{~g}_{\text {tanaman }}{ }^{-1}$ dan diulang lagi dengan dosis yang sama setelah 2 minggu. Penyiraman dilakukan setiap minggu sekali (jika dalam seminggu tidak ada hujan).

Pembumbunan juga dilakukan agar
perakarannya berkembang dengan baik (Hariyadi, 2005; Pranowo et al., 2007). Gulma yang ada di lahan dibersihkan secara manual $(0-4$ MST) dan kimiawi (6 MST). Pengendalian hama dan penyaki tanaman dilakukan secara manual, karena persentase serangan sangat rendah.

Pemanenan dilakukan dengan memetik buah yang masak secara langsung dari malainya. Buah tidak masak secara bersamaan dalam satu malainya, sehingga pemanenan dilakukan per buah. Buah yang dipanen diekstraksi, benihnya dikeringanginkan di tempat teduh selama $\pm 3-4$ hari (Kadar air biji \pm $7 \%$ ) (Hasnam, 2007), kemudian benih disimpan dalam kantong plastik yang berklip (sealed) pada kondisi suhu kamar $\pm 27-30^{\circ} \mathrm{C}$.

Pengamatan dilakukan pada akhir pembibitan dan pengamatan di lapangan. Pengamatan di lapangan dilakukan setiap dua minggu. Pengamatan pada akhir pembibitan dilakukan terhadap enam tanaman contoh meliputi peubah: (1) tinggi bibit (cm) dilakukan dengan mengukur bibit dari permukaan tanah sampai titik tumbuh, (2) jumlah daun, (3) panjang akar $(\mathrm{cm})$; mengukur panjang akar primer terpanjang dari pangkal sampai ujung akar, (4) panjang tajuk $(\mathrm{cm})$; mengukur dari pangkal batang sampai ujung batang, (5) bobot kering akar (g); dilakukan dengan cara menimbang akar yang telah dioven pada suhu $60^{\circ} \mathrm{C}$ selama 4 hari, dan (6) bobot kering tajuk (g); dilakukan dengan cara menimbang tajuk yang telah dioven pada suhu $60^{\circ} \mathrm{C}$ selama 4 hari.
Pengamatan di lapangan dilakukan pada fase vegetatif dan generatif. Peubah-peubah yang diamati adalah: (1) tinggi tanaman $(\mathrm{cm})$; diukur pada batang utama mulai dari permukaan tanah sampai ujung tanaman,(2)jumlah daun,(3)jumlah cabang primer,(4) jumlah cabang produktif, (5) jumlah malai per cabang, (6) waktu $50 \%$ berbunga (hari) untuk setiap aksesi, (7) waktu bunga mekar pertama; mencatat waktu (hari) saat bunga tanaman (jantan, betina, hermaprodit) mekar pertama kali untuk setiap aksesi, (8) jumlah bunga betina, jantan dan hermaprodit; menghitung jumlah bunga jantan, betina dan hermaprodit yang dihasilkan oleh setiap tanaman pada tiga malai yang terbentuk pertama kali, (9) jumlah tanaman yang berbunga untuk setiap aksesi, (10) jumlah buah per malai; menghitung jumlah buah yang dihasilkan oleh setiap tanaman pada tiga malai pertama, (11) jumlah buah per tanaman; menghitung jumlah buah yang diproduksi oleh setiap tanaman contoh, (12) jumlah buah per bulan; menghitung jumlah buah yang dipanen setiap bulan untuk setiap aksesi, dan (13) produksi biji per tanaman; menimbang bobot biji kering yang diproduksi oleh setiap tanaman. Analisis data dilakukan dengan uji-F diikuti uji jarak berganda Duncan (DMRT) untuk peubah yang berbeda nyata.

\section{HASIL DAN PEMBAHASAN}

\section{Keragaan Bibit Jarak Pagar}

Terdapat perbedaan tinggi bibit antar aksesi dengan kisaran $31-59 \mathrm{~cm}$. Menurut Santosa dan Purwoko (2008) perbedaan tinggi semai disebabkan perbedaan dalam kecepatan berkecambah/ munculnya semai di permukaan tanah. Seperti yang terlihat pada Tabel 1, aksesi yang memiliki rata-rata tinggi bibit terbesar adalah Dompu $(59.25 \mathrm{~cm})$ kemudian aksesi Bogor 80-11-5 $(57 \mathrm{~cm})$, sedangkan yang terkecil adalah IP-2P 110-1-4 $(31.40 \mathrm{~cm})$. Hal ini menunjukkan bahwa aksesi Dompu dan Bogor 80-11-5 memiliki daya berkecambah yang lebih cepat dibandingkan dengan aksesi yang lain, sedangkan aksesi IP-2P 110-1-4 memiliki daya berkecambah paling lambat dibandingkan dengan aksesi lainnya.

Aksesi yang memiliki rata-rata jumlah daun terbanyak adalah Bontomaramu 1-1 dan Bone keduanya memiliki rata-rata jumlah daun yang sama yaitu 24 (Tabel 1), sedangkan yang memiliki jumlah daun paling sedikit adalah IP-2P 110-1-4 (14.17). Aksesi IP-2P 110-1-4 memiliki rata-rata jumlah daun paling rendah dan rata-rata tinggi tanaman yang paling rendah. Aksesi Bontomaramu 1-1 dan Bone yang memiliki rata-rata jumlah daun tertinggi, 
Tabel 1. Nilai rataan karakter vegetatif beberapa aksesi jarak pagar saat 8 MST

\begin{tabular}{lllllllll}
\hline Jenis Aksesi & TB $(\mathrm{cm})$ & JD & PT $(\mathrm{cm})$ & PAP $(\mathrm{cm})$ & BBT $(\mathrm{g})$ & BKT $(\mathrm{g})$ & BBA $(\mathrm{g})$ & BKA $(\mathrm{g})$ \\
\hline Aceh Besar & 45 & 21.33 & 49.25 & 23.8 & 80.95 & 41.63 & 6.67 & 1.64 \\
Bengkulu 3 & 39.33 & 18 & 43 & 39.33 & 72.24 & 27.3 & 6 & 1.3 \\
Bima & 54 & 21.33 & 35.25 & 22.83 & 106.81 & 40.83 & 10.04 & 2.48 \\
Bogor 80-11-5 & 57 & 22.5 & 63.33 & 21.5 & 113.35 & 53.52 & 9.78 & 3.4 \\
Bone & 53 & 24 & 52.17 & 27.67 & 80.8 & 38.72 & 11.96 & 4.45 \\
Bontomaramu 1-1 & 53 & 24 & 52.17 & 27.67 & 124.96 & 42.5 & 13.33 & 4.32 \\
Dompu & 59.25 & 21.5 & 62.33 & 20.17 & 113.64 & 49.61 & 9.88 & 2.9 \\
Gunung Tambora & 48.33 & 22.17 & 52.8 & 20.6 & 81.62 & 44.66 & 2.75 & 3.7 \\
IP-2P 110-1-4 & 31.4 & 14.17 & 32.25 & 15 & 45.2 & 16.38 & 8.68 & 0.8 \\
Lombok 59-1-2 & 42.75 & 23.33 & 47 & 20.6 & 84.36 & 33.86 & 9.28 & 2.61 \\
Sukabumi & 50.75 & 20.5 & 59 & 27.5 & 98.02 & 29.8 & 8.39 & 1.9 \\
Rataan & 48.53 & 21.17 & 49.87 & 24.24 & 91.09 & 38.07 & 8.79 & 2.68 \\
\hline
\end{tabular}

Keterangan $: \mathrm{TB}=$ tinggi bibit, $\mathrm{JD}=$ jumlah daun, $\mathrm{PT}=$ panjang tajuk, $\mathrm{PAP}=$ panjang akar primer, $\mathrm{BBT}=$ bobot basah tajuk, $\mathrm{BKT}=$ bobot kering tajuk, $\mathrm{BBA}=$ bobot basah akar, $\mathrm{BKA}=$ bobot kering akar

rata-rata tinggi tanamannya lebih besar dibandingkan dengan Aceh Besar, Bengkulu 3, Lombok 59-12, Sukabumi, dan IP-2P 110-1-4 meskipun tidak melebihi Bima, Bogor 80-11-5, Gunung Tambora, dan Dompu.

Panjang tajuk bibit antar aksesi jarak pagar memiliki perbedaan yang nyata dengan kisaran panjang $32-63 \mathrm{~cm}$, kecuali untuk aksesi Aceh Besar, Bone, Bontomaramu 1-1 dan Gunung Tambora dengan masing-masing nilai sebesar 49.25, 52.17, 52.17 dan $52.80 \mathrm{~cm}$. Aksesi yang memiliki tajuk paling panjang adalah aksesi Bogor 80-11-5, sedangkan aksesi yang paling pendek dibandingkan dengan aksesi lainnya adalah aksesi IP-2P 110-1-4. Panjang akar bibit antar aksesi jarak pagar berkisar $15-39 \mathrm{~cm}$. Aksesi yang memiliki akar primer terpanjang adalah Bengkulu $3(39.33 \mathrm{~cm})$, sedangkan yang akar primernya terpendek adalah IP-2P 110-1-4 $(15 \mathrm{~cm})$ (Tabel 1).

Aksesi yang memiliki bobot basah (BB) tajuk terbesar adalah aksesi Bontomaramu 1-1 dengan nilai BB tajuk 124.96 g kemudian aksesi Dompu dan Bogor 80-11-5 masing-masing $113.64 \mathrm{~g}$ dan $113.35 \mathrm{~g}$, sedangkan BB tajuk terkecil adalah aksesi IP-2P 1101-4 dengan nilai BB tajuk $45.20 \mathrm{~g}$.

Seperti yang terlihat pada Tabel 1 bahwa aksesi yang memiliki BB akar maksimum adalah aksesi Bontomaramu 1-1 senilai $13.33 \mathrm{~g}$, kemudian Bone, Bima, Dompu dan Bogor 80-11-5 dengan nilai BB akar masing-masing 11.96, 10.04, 9.88 dan $9.78 \mathrm{~g}$. Aksesi yang memiliki BB akar minimum adalah aksesi Gunung Tambora dengan nilai BB akar 2.75 g. Hasil ini menunjukkan bahwa aksesi Dompu dan Bogor 8011-5 adalah aksesi yang BB tanamannya lebih baik dibandingkan dengan aksesi-aksesi lain, karena kedua aksesi tersebut memiliki BB tajuk dan akar yang lebih besar.

Aksesi yang memiliki pertumbuhan bibit terbaik secara berurutan adalah Bontomaramu 11 dan Bogor 80-11-5, karena keduanya memiliki karakter yang tergolong baik untuk tujuh karakter dari delapan karakter pengamatan. Aksesi yang memiliki pertumbuhan bibit kurang baik dibandingkan dengan aksesi yang lain adalah IP-2P 110-1-4 dan Bengkulu 3. Kedua aksesi tersebut memiliki nilai terendah untuk tujuh karakter dari delapan karakter pengamatan.

\section{Keragaan Fase Vegetatif Tanaman Jarak Pagar di Lapangan}

Secara umum tinggi aksesi jarak pagar mengalami peningkatan. Berdasarkan hasil analisis ragam (Tabel 2), jenis aksesi sangat berpengaruh nyata terhadap tinggi tanaman mulai 0 MST sampai dengan 16 MST. Menurut Yahya (1987) bahwa varietas berpengaruh nyata terhadap tinggi tanaman kelapa. Aksesi jarak pagar yang memiliki rataan tinggi tanaman maksimum adalah Gunung Tambora (82.09 $\mathrm{cm})$ kemudian aksesi Bogor 80-11-5 $(78.26 \mathrm{~cm})$, sedangkan aksesi yang memiliki rataan tinggi tanaman minimum adalah aksesi Lombok 59-1-2 $(54.18 \mathrm{~cm})$ kemudian aksesi Luwu Utara $(59.89 \mathrm{~cm})$.

Gambar 1, menunjukkan pertumbuhan tinggi 
Tabel 2. Rekapitulasi hasil analisis ragam pengaruh aksesi jarak pagar terhadap pertumbuhan pada fase vegetatif

\begin{tabular}{lccc}
\hline Karakter & $\begin{array}{c}\text { Pengaruh } \\
\text { Pengelompokan }\end{array}$ & $\begin{array}{c}\text { Pengaruh } \\
\text { Aksesi }\end{array}$ & $\begin{array}{c}\text { KK } \\
(\%)^{\circ}\end{array}$ \\
\hline TT (16 MST) & tn & $* *$ & 13.38 \\
JD (16 MST) & tn & $* *$ & 18.78 \\
JC (12 MST) & $* *$ & tn & 18.08 \\
\hline
\end{tabular}

Keterangan : TT $=$ tinggi tanaman, JD $=$ jumlah daun, $\mathrm{JC}=$ jumlah cabang primer, $\mathrm{tn}=$ tidak nyata, $*=$ nyata, $* *=$ sangat nyata, $\mathrm{MST}=$ minggu setelah tanam

o = hasil setelah transformasi dengan akar $(\mathrm{x}+0.5)$

beberapa aksesi jarak pagar selama 16 MST. Laju pertumbuhan tinggi tanaman yang tergolong signifikan dari 0 - 4 MST, kemudian melambat kembali setelah 4 MST saat aksesi jarak pagar mengalami fase generatif (tanaman mulai berbunga).

Aksesi Lombok 59-1-2 merupakan aksesi yang memiliki jumlah daun maksimum saat 14 MST senilai 155.33, sedangkan aksesi Bone memiliki jumlah daun yang minimum senilai 157.67. Perbedaan jumlah daun antar aksesi jarak pagar dipengaruhi oleh faktor genetik dan lingkungan. Setiap aksesi akan berbeda dalam merespon kondisi lingkungan.

Gambar 2 memperlihatkan, bahwa jumlah daun mengalami peningkatan yang signifikan pada 0 - 4 MST kemudian menurun lagi jumlahnya sampai 8 MST, kecuali aksesi IP-2P 110-1-4 masih meningkat sampai 6 MST. Saat 6 MST rata-rata jumlah daun mengalami penurunan kecuali aksesi Bima, IP-2P

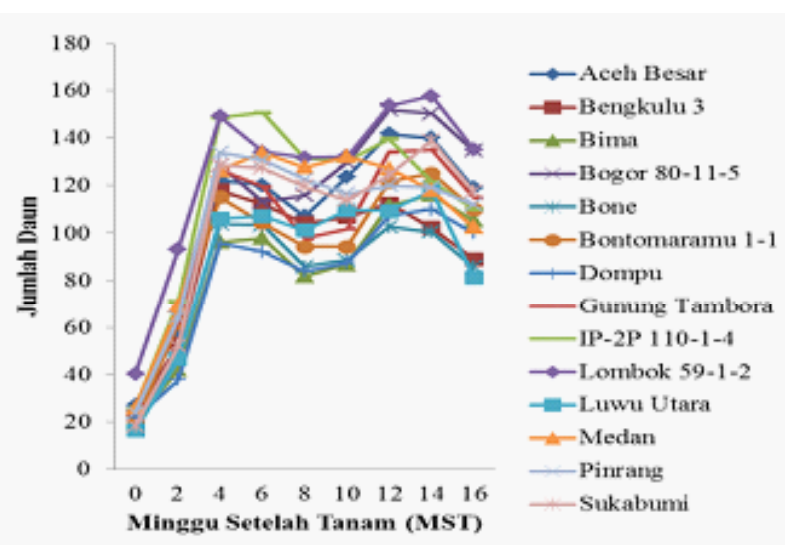

Gambar 2. Pertumbuhan daun beberapa aksesi jarak pagar selama $16 \mathrm{MST}$

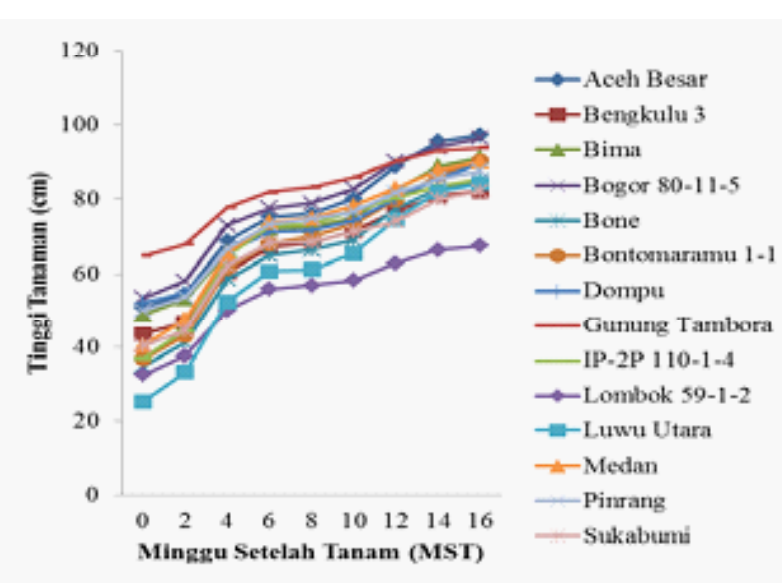

Gambar 1. Pertumbuhan tinggi beberapa aksesi jarak pagar selama 16 MST

110-1-4, Luwu Utara dan Medan. Hal ini disebabkan genangan air pada areal pertanaman jarak pagar akibat air hujan yang turun pada malam harinya. Yahya (1987) menyatakan bahwa air yang tergenang mengakibatkan kekurangan oksigen, sehingga proses pernapasan akan terganggu. Sumanto (2006) menambahkan bahwa tanaman jarak pagar tidak menghendaki kondisi media yang tergenang.

Hasil penelitian menunjukkan bahwa aksesi berpengaruh nyata terhadap jumlah cabang primer pada saat 4, 8 dan 16 MST, berpengaruh sangat nyata pada saat $10 \mathrm{MST}$ dan tidak berpengaruh nyata saat 12 - 14 MST. Saat 16 MST aksesi yang memiliki jumlah cabang primer paling banyak adalah IP-2P 110-1-4 dengan nilai 9.56 dan yang terkecil adalah Bone dengan nilai 5.33 seperti yang terlihat pada Gambar 3. Hartati et al. (2009) menyatakan bahwa terdapat keragaman yang tinggi antar aksesi jarak pagar pada karakter jumlah cabang.

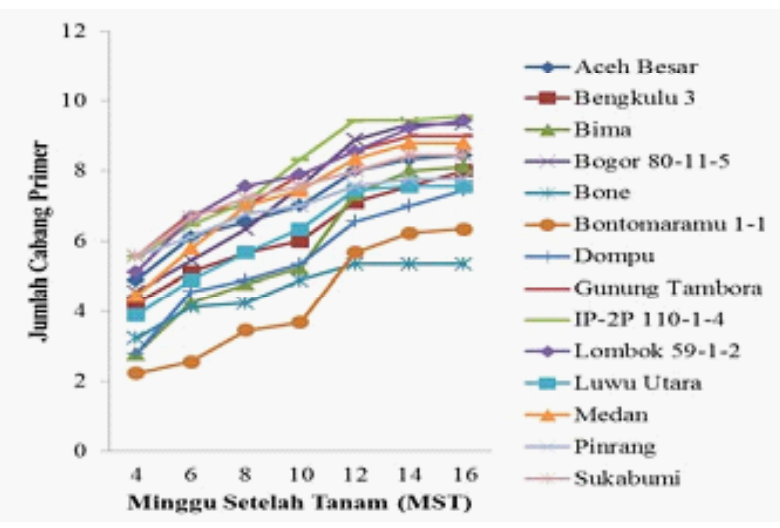

Gambar 3. Peningkatan jumlah cabang primer beberapa aksesi jarak pagar selama 16 MST 
Tabel 3. Rekapitulasi hasil analisis ragam pengaruh aksesi jarak pagar terhadap pertumbuhan pada fase generatif

\begin{tabular}{lccc}
\hline Karakter & $\begin{array}{c}\text { Pengaruh } \\
\text { Pengelompokan }\end{array}$ & $\begin{array}{c}\text { Pengaruh } \\
\text { Aksesi }\end{array}$ & $\begin{array}{c}\text { KK } \\
(\%)^{\circ}\end{array}$ \\
\hline C.ProdI & tn & $* *$ & 13.79 \\
MalaiI & $*$ & $* *$ & 13.88 \\
B. Jantan^ & $* *$ & $* *$ & 26.23 \\
B. Betina $^{\wedge}$ & tn & $* *$ & 24.82 \\
Buah^ $^{\wedge}$ & tn & $* *$ & 28.48 \\
BuahI $_{\text {BBKI }}$ & tn & $* *$ & 35.20 \\
\hline
\end{tabular}

Keterangan : $\mathrm{C}=$ cabang, Prod $=$ produktif, $\mathrm{B}=$ bunga, $\wedge=$ per malai, $\mathrm{I}=$ per tanaman, $\mathrm{tn}=$ tidak nyata, $*=$ nyata, $* *=$ sangat nyata, ${ }^{\circ}=$ hasil transformasi dengan akar $(\mathrm{x}+0.5)$

Cabang jarak pagar tidak semuanya memiliki malai, karena ada yang dorman atau bukan cabang produktif. Seperti pada penelitian ini, aksesi IP2P 110-1-4 yang jumlah cabang primernya 9.56 memiliki jumlah cabang produktif 2.44 lebih sedikit dibandingkan aksesi Sukabumi yang jumlah cabang produktifnya 3.67 meskipun jumlah cabang primernya 8.44 .

\section{Keragaan Fase Generatif Aksesi Jarak Pagar di Lapangan}

Hasil penelitian menunjukkan bahwa aksesi yang semua tanamannya dapat berbunga dan berbuah adalah Aceh Besar, Bengkulu 3, Bogor 80-11-5, Bontomaramu, Gunung Tambora, IP-2P 110-1-4, Luwu Utara dan Medan, sedangkan aksesi yang paling sedikit menghasilkan bunga dan buah adalah Dompu dengan persentase bunga dan buah masing- masing 77.78 dan 66.67\%, kemudian aksesi Bima, Bone, Lombok 59-1-2 dan Pinrang dengan persentase bunga dan buah sama masing-masing $88.89 \%$. Tanaman yang tidak menghasilkan bunga mengindikasikan bahwa pertumbuhannya terhambat, dengan indikator tanamannya pendek (Lombok 59-1-2) dan jumlah daun lebih sedikit (Bone dan Dompu).

Hasil penelitian menunjukkan bahwa waktu berbunga aksesi-aksesi yang diuji bervariasi antara 59 - 99 hari setelah tanam (HST) (Tabel 4). Aksesi yang umur berbunganya paling cepat adalah aksesi Pinrang (29 HST) kemudian IP-2P 110-1-4 (31 HST), sedangkan aksesi yang umur berbunganya lambat adalah aksesi Dompu dan Lombok 59-1-2 (masing- masing 69 HST). Aksesi yang pertamakali bunganya mekar bervariasi dengan kisaran (36 - 75 HST). Aksesi yang paling awal mekar yaitu aksesi IP-2P 110-1-4 (36 HST), sedangkan yang paling akhir mekar adalah aksesi Bengkulu 3 (75 HST) (Tabel 4). Aksesi Pinrang, Medan, Bogor 80-11-5 dan Bontomaramu 1-1 memiliki kesamaan hari bunga mekar pertama yaitu 43 HST. Menurut (2009), perbedaan waktu mekar bunga jarak pagar dalam satu malai diduga disebabkan oleh perbedaan fase perkembangan, kuncup yang terbentuk lebih awal akan mekar lebih dahulu.

Menurut Asbani dan Winarno (2009), tipe pembungaan jarak pagar ada dua tipe, yaitu monoecious/ unisexual dan andromonoecious. Aksesi pada penelitian ini yang memiliki tipe pembungaan andromonoecious adalah Bima, Gunung Tambora, dan Lombok 59-1-2 sementara aksesi lainnya bertipe monoecious. Tipe pembungaan untuk aksesi Gunung Tambora dan Bima hasilnya tidak sama dengan penelitian Misnen (2010), bahwa aksesi Gunung Tambora dan Bima memiliki tipe pembungaan andromonoecious. Hal ini diduga karena adanya perbedaan faktor lingkungan seperti curah hujan selama fase generatif. Bunga yang mekar pada penelitian ini menunjukkan dua tipe pemekaran bunga, yaitu tipe protandri dan protagini. Hasil penelitian menunjukkan bunga jarak pagar mekar lebih cenderung bertipe protandri.

Hasil analisis ragam menunjukan aksesi berpengaruh sangatnyata terhadapjumlah bunga betina/ hermaprodit dan bunga jantan. Seperti yang terlihat pada Tabel 5, bahwa aksesi yang memiliki jumlah bunga jantan paling banyak adalah Bontomaramu 1-1 (137.78 bunga), sedangkan yang paling sedikit adalah aksesi Dompu (47.78 bunga). Aksesi yang memiliki jumlah bunga betina terbanyak adalah aksesi Bontomaramu 1-1 (8.29 bunga) kemudian Medan (7.78 bunga) dan Bengkulu 3 ( 7.37 bunga), sedangkan yang tersedikit adalah Bone (3.11 bunga) dan Bima (3.78 bunga).

Hasil penelitian menunjukkan bahwa rasio jumlah bunga betina/ hermaprodit dengan bunga jantan yaitu 1:15 seperti yang terlihat pada Tabel 5. Hasil ini sesuai dengan penelitian Hartati (2007) yang menyatakan bahwa rasio bunga betina dan jantan yaitu $1: 15-30$.

Tidak semua bunga yang terbentuk dapat berkembang menjadi buah setelah antesis, sehingga belum tentu tanaman yang memiliki malai yang banyak akan menghasilkan buah yang banyak. Seperti halnya pada penelitian ini bahwa aksesi Sukabumi yang memiliki 6.89 malai menghasilkan 17.33 buah tanaman $^{-1}$ lebih rendah dibandingkan dengan aksesi 
Tabel 4. Persentase jumlah tanaman berbunga dan berbuah serta waktu berbunga dan waktu bunga mekar pertama 14 aksesi jarak pagar

\begin{tabular}{lcccc}
\hline Jenis Aksesi & $\begin{array}{c}\text { Tanaman Berbunga } \\
(\%)\end{array}$ & $\begin{array}{c}\text { Tanaman Berbuah } \\
(\%)\end{array}$ & $\begin{array}{c}\text { Waktu 50 \% } \\
\text { Berbunga }\end{array}$ & $\begin{array}{c}\text { Waktu Mekar } \\
\text { Pertama (HST) }\end{array}$ \\
\hline Aceh Besar & 100 & 100 & 50 & 46 \\
Bengkulu 3 & 100 & 100 & 46 & 75 \\
Bima & 88.89 & 88.89 & 53 & 51 \\
Bogor 80-11-5 & 100 & 100 & 38 & 43 \\
Bone & 88.89 & 88.89 & 54 & 44 \\
B.maramu 1-1 & 100 & 100 & 41 & 43 \\
Dompu & 77.78 & 66.67 & 69 & 47 \\
G. Tambora & 100 & 100 & 46 & 52 \\
IP-2P 110-1-4 & 100 & 100 & 31 & 36 \\
L.bok 59-1-2 & 88.89 & 88.89 & 69 & 47 \\
L. Utara & 100 & 100 & 54 & 69 \\
Medan & 100 & 100 & 38 & 43 \\
Pinrang & 88.89 & 88.89 & 29 & 43 \\
Sukabumi & 100 & 88.89 & 43 & 44 \\
\hline
\end{tabular}

Tabel 5. Jumlah bunga betina/hermaprodit, jumlah malai, dan jumlah cabang produktif 14 aksesi jarak pagar

\begin{tabular}{lllll}
\hline Jenis Aksesi & \multicolumn{1}{c}{ JBJ } & \multicolumn{1}{c}{ JB } & JM & JCP \\
\hline Aceh Besar & $73.63 \mathrm{bc}$ & $4.59 \mathrm{bcd}$ & $2.56 \mathrm{c}$ & $1.56 \mathrm{bc}$ \\
Bengkulu 3 & $75.74 \mathrm{bc}$ & $7.37 \mathrm{ab}$ & $4.33 \mathrm{bc}$ & $1.67 \mathrm{bc}$ \\
Bima & $70.70 \mathrm{bc}$ & $3.78 \mathrm{~cd}$ & $3.22 \mathrm{c}$ & $1.11 \mathrm{c}$ \\
Bogor 80-11-5 & $76.48 \mathrm{bc}$ & $6.78 \mathrm{abc}$ & $8.11 \mathrm{a}$ & $3.67 \mathrm{a}$ \\
Bone & $69.19 \mathrm{bc}$ & $3.11 \mathrm{~d}$ & $2.33 \mathrm{c}$ & $1.11 \mathrm{c}$ \\
B.maramu 1-1 & $137.78 \mathrm{a}$ & $8.29 \mathrm{a}$ & $5.44 \mathrm{abc}$ & $2.11 \mathrm{abc}$ \\
Dompu & $47.78 \mathrm{c}$ & $4.04 \mathrm{~cd}$ & $3.11 \mathrm{c}$ & $1.22 \mathrm{c}$ \\
G. Tambora & $87.41 \mathrm{~b}$ & $4.92 \mathrm{bcd}$ & $2.67 \mathrm{c}$ & $1.44 \mathrm{c}$ \\
IP-2P 110-1-4 & $80.30 \mathrm{bc}$ & $6.92 \mathrm{abc}$ & $7.22 \mathrm{ab}$ & $2.44 \mathrm{abc}$ \\
L.bok 59-1-2 & $85.67 \mathrm{~b}$ & $6.92 \mathrm{abc}$ & $4.00 \mathrm{bc}$ & $1.56 \mathrm{bc}$ \\
L. Utara & $82.04 \mathrm{bc}$ & $5.37 \mathrm{abcd}$ & $3.00 \mathrm{c}$ & $1.22 \mathrm{c}$ \\
Medan & $83.44 \mathrm{bc}$ & $7.78 \mathrm{ab}$ & $7.33 \mathrm{ab}$ & $3.44 \mathrm{a}$ \\
Pinrang & $84.93 \mathrm{~b}$ & $6.63 \mathrm{abc}$ & $7.22 \mathrm{ab}$ & $3.11 \mathrm{ab}$ \\
Sukabumi & $88.52 \mathrm{~b}$ & $6.81 \mathrm{abc}$ & $6.89 \mathrm{ab}$ & $3.67 \mathrm{ab}$ \\
Rataan & 81.68 & 5.46 & 4.82 & 2.09 \\
\hline
\end{tabular}

Keterangan : JBJ $=$ jumlah bunga jantan, $\mathrm{JB}=$ jumlah bunga betina/ hermaprodit, $\mathrm{JM}=$ jumlah malai, $\mathrm{JCP}=$ jumlah cabang produktif

Bontomaramu 1-1 yang memiliki 5.44 malai yang bisa menghasilkan 25.33 buah tanaman ${ }^{-1}$.

Hasil analisis ragam menunjukan bahwa aksesi berpengaruh nyata terhadap jumlah cabang produktif. Rata-rata jumlah cabang produktif tertinggi adalah aksesi Bogor 80-11-5 dan Sukabumi masing- 
Tabel 6. Jumlah Buah per Malai, jumlah buah per tanaman, dan bobot biji per tanaman 14 aksesi jarak pagar

\begin{tabular}{llcc}
\hline Jenis Aksesi & JBM & JBT & BBK $(\mathrm{g})$ \\
\hline Aceh Besar & $3.852 \mathrm{~b}$ & $11.778 \mathrm{c}$ & $13.021 \mathrm{~cd}$ \\
Bengkulu 3 & $5.185 \mathrm{ab}$ & $16.889 \mathrm{bc}$ & $14.917 \mathrm{~cd}$ \\
Bima & $2.593 \mathrm{~b}$ & $8.667 \mathrm{c}$ & $6.702 \mathrm{~d}$ \\
Bogor 110-1-4 & $5.111 \mathrm{ab}$ & $25.778 \mathrm{ab}$ & $28.454 \mathrm{ab}$ \\
Bone & $2.593 \mathrm{~b}$ & $9.000 \mathrm{c}$ & $12.327 \mathrm{~cd}$ \\
B.maramu 1-1 & $7.148 \mathrm{a}$ & $25.333 \mathrm{ab}$ & $21.151 \mathrm{abc}$ \\
Dompu & $3.148 \mathrm{~b}$ & $11.111 \mathrm{c}$ & $13.551 \mathrm{~cd}$ \\
G. Tambora & $3.222 \mathrm{~b}$ & $12.333 \mathrm{c}$ & $14.389 \mathrm{~cd}$ \\
IP-2P 110-1-4 & $5.000 \mathrm{ab}$ & $20.111 \mathrm{abc}$ & $18.116 \mathrm{bcd}$ \\
Lombok 59-1-2 & $4.037 \mathrm{~b}$ & $13.222 \mathrm{c}$ & $15.869 \mathrm{~cd}$ \\
Luwu Utara & $2.963 \mathrm{~b}$ & $9.222 \mathrm{c}$ & $12.759 \mathrm{~cd}$ \\
Medan & $6.926 \mathrm{a}$ & $29.222 \mathrm{a}$ & $31.094 \mathrm{a}$ \\
Pinrang & $4.667 \mathrm{ab}$ & $18.444 \mathrm{abc}$ & $20.043 \mathrm{abc}$ \\
Sukabumi & $4.667 \mathrm{ab}$ & $17.333 \mathrm{abc}$ & $19.289 \mathrm{abcd}$ \\
Rataan & 4.14 & 14.64 & 17.26 \\
\hline
\end{tabular}

Keterangan : $\mathrm{JBM}=$ jumlah buah per malai, JBT $=$ jumlah buah per tanaman, $\mathrm{BBK}=$ bobot biji kering per tanaman

masing 3.67 cabang kemudian Medan (3.44 cabang), sedangkan aksesi yang memiliki jumlah cabang produktif terendah adalah aksesi Bone dan Bima yang jumlah cabang yang sama (1.11 cabang) (Tabel 5). Hartati et al.(2009) menyatakan bahwa jumlah cabang produktif nyata berkorelasi dengan komponen hasil.

Hasil penelitian ini menunjukkan bahwa aksesi Bogor 80-11-5 dan Medan yang memiliki cabang produktif lebih banyak dibandingkan aksesi lainnya ternyata juga menghasilkan jumlah buah per tanaman yang lebih banyak, sedangkan aksesi Bone dan Bima dengan jumlah cabang produktif lebih sedikit juga menghasilkan buah per tanamannya juga sedikit.

Aksesi berpengaruh sangat nyata terhadap jumlah malai tanaman. Seperti yang terlihat pada Tabel 5 menunjukan bahwa aksesi Bogor 80-11-5 memiliki nilai rata-rata jumlah malai per tanaman tertinggi sebesar 8.11 malai tanaman $^{-1}$ kemudian Medan (7.33 malai tanaman ${ }^{-1}$ dan IP-2P 110-1-4 (7.22 malai tanaman $\left.{ }^{-1}\right)$, sedangkan yang terendah adalah aksesi Bone (2.33 malai tanaman $\left.{ }^{-1}\right)$ kemudian Aceh Besar (2.56 malai tanaman $\left.{ }^{-1}\right)$.

Hasil evaluasi aksesi jarak pagar terhadap karakter jumlah bunga jantan dan betina/ hermaprodit, jumlah malai per tanaman, dan jumlah cabang produktif per tanaman, maka aksesi yang tergolong baik adalah Bogor 80-11-5 dan Medan, sedangkan aksesi yang tergolong kurang baik adalah aksesi Bima dan Bone.

\section{Pembuahan Jarak Pagar}

Aksesi berpengaruh sangat nyata terhadap jumlah buah per malai. Hasil penelitian menunjukan bahwa aksesi yang memiliki rata-rata jumlah buah per malai terbesar adalah aksesi Medan kemudian aksesi Bontomaramu 1-1 dan Bogor 80-11-5 masing-masing nilainya $6.92,7.14$ dan 5.11 buah malai $^{-1}$, sedangkan

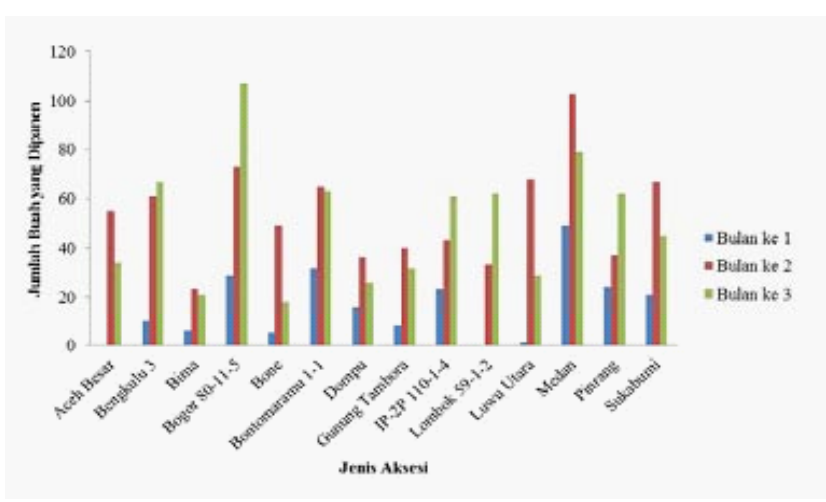

Gambar 4. Jumlah buah panen per bulan pada beberapa aksesi jarak pagar 
Tabel 7. Rekapitulasi Nilai Peringkat 14 Aksesi Jarak Pagar terhadap Delapan Karakter Penyeleksi Jarak Pagar di Daerah Pesisir Pantai

\begin{tabular}{lccccccccc}
\hline Jenis Aksesi & TT & JC & JCP & JM1) & JBB2) & JB2) & JB1) & BBK1) & KT \\
\hline Aceh Besar & $\sqrt{ }$ & - & - & - & - & - & - & - & 1 \\
Bengkulu 3 & - & - & - & - & $\sqrt{ }$ & - & $\sqrt{ }$ & - & 2 \\
Bima & $\sqrt{ }$ & - & - & - & - & - & - & - & 1 \\
Bogor 110-1-4 & $\sqrt{ }$ & $\sqrt{ }$ & $\sqrt{ }$ & $\sqrt{ }$ & $\sqrt{ }$ & $\sqrt{ }$ & $\sqrt{ }$ & $\sqrt{ }$ & 8 \\
Bone & - & - & - & - & - & - & - & - & 0 \\
B.maramu 1-1 & - & - & $\sqrt{ }$ & $\sqrt{ }$ & $\sqrt{ }$ & $\sqrt{ }$ & $\sqrt{ }$ & $\sqrt{ }$ & 6 \\
Dompu & - & - & - & - & - & - & - & - & 0 \\
G. Tambora & $\sqrt{ }$ & $\sqrt{ }$ & - & - & - & - & - & - & 2 \\
IP-2P 110-1-4 & - & $\sqrt{ }$ & $\sqrt{ }$ & $\sqrt{ }$ & $\sqrt{ }$ & $\sqrt{ }$ & $\sqrt{ }$ & $\sqrt{ }$ & 7 \\
Lombok 59-1-2 & - & $\sqrt{ }$ & - & - & $\sqrt{ }$ & - & - & - & 2 \\
Luwu Utara & - & - & - & - & - & - & - & - & 0 \\
Medan & - & - & $\sqrt{ }$ & $\sqrt{ }$ & $\sqrt{ }$ & $\sqrt{ }$ & $\sqrt{ }$ & $\sqrt{ }$ & 6 \\
Pinrang & $\sqrt{ }$ & - & $\sqrt{ }$ & $\sqrt{ }$ & - & $\sqrt{ }$ & - & $\sqrt{ }$ & 5 \\
Sukabumi & - & $\sqrt{ }$ & $\sqrt{ }$ & $\sqrt{ }$ & - & - & - & $\sqrt{ }$ & 4 \\
\hline
\end{tabular}

Keterangan : $\mathrm{TT}=$ tinggi tanaman, $\mathrm{JC}=$ jumlah cabang primer, $\mathrm{JCP}=$ jumlah cabang produktif, JM $=$ jumlah malai, JBB $=$ jumlah bunga betina, $\mathrm{JB}=$ jumlah buah, $\mathrm{BBK}=$ bobot biji kering, $\mathrm{KT}=$ karakter tertinggi, $\sqrt{ }=$ menunjukkan nilai tertinggi yang dimiliki oleh masing- masing genotipe pada setiap peubah penyeleksi, ${ }^{1)}$ per tanaman, ${ }^{2}$ ) per malai

yang terkecil adalah Bima dan Bone masing-masing sebanyak 2.59 buah malai ${ }^{-1}$ seperti yang terlihat pada Tabel 6. Semakin banyak jumlah bunga betina maka akan semakin banyak pula jumlah buah yang dihasilkan, karena bunga betinalah yang akan menjadi buah setelah terjadi antesis. Meskipun demikian tidak semua bunga menghasilkan buah karena pengaruh beberapa faktor, antara lain adalah bunga betina yang telah mengalami penyerbukan gagal berkembang menjadi buah, bunga betina terkena penyakit seperti tepung putih, buah yang masih inisiasi menguning/ diserang kepik penghisap.

Aksesi berpengaruh sangat nyata terhadap jumlah buah per tanaman. Secara umum jumlah buah per tanaman setiap aksesi bervariasi. Aksesi yang memiliki jumlah buah per tanaman terbesar adalah aksesi Medan (29.22 buah tanaman ${ }^{-1}$ ) kemudian Bogor 80-11-5 (25.78 buah tanaman $\left.{ }^{-1}\right)$, sedangkan yang terkecil adalah aksesi Bima (8.67 $\mathrm{g}$ tanaman $\left.^{-1}\right)$ kemudian Bone (9 buah tanaman ${ }^{-1}$ ) (Tabel 6). Aksesi Medan menghasilkan buah lebih banyak karena bunga betina yang terbentuk banyak.

Hasil penelitian menunjukkan bahwa jumlah buah yang dapat dipanen setiap bulan bervariasi pada setiap aksesi berkisar $1-107$ buah dengan rata-rata 40 buah/bulan. Rata-rata jumlah buah yang paling banyak dipanen setiap bulan adalah aksesi Medan sebanyak
77 buah kemudian Bogor 80-11-5 sebanyak 69.67, sedangkan jumlah buah yang paling sedikit dipanen per bulannya adalah aksesi Bone sebanyak 16.67 buah kemudian Dompu sebanyak 24.00 buah (Gambar 4).

Biji yang dihasilkan dalam satu buah jarak pagar bervariasi antara $1-4 \mathrm{biji} / \mathrm{buah}$ dengan bobot kering biji berkisar $6.70-31.09 \mathrm{~g}$ tanaman $^{-1}$ dan bobot rata-rata $17.26 \mathrm{~g}_{\text {tanaman }}{ }^{-1}$. Bobot biji kering tertinggi dimiliki oleh Medan, kemudian aksesi Bogor 80-115 dengan nilai rata-rata bobot kering masing-masing sebesar 31.09 dan $28.45 \mathrm{~g}$ tanaman $^{-1}$, sedangkan bobot biji kering terendah terdapat pada aksesi Bima (7.19 $\mathrm{g}$ tanaman $^{-1}$ ) kemudian Aceh Besar (11.345 $\mathrm{g}$ tanaman $^{-}$ $\left.{ }^{1}\right)$. Aksesi Medan dan Bogor 80-11-5 memiliki BBK yang terbesar, karena jumlah buah yang dipanen juga lebih banyak dibandingkan dengan aksesi lainnya (Tabel 6).

\section{Aksesi Toleran di Daerah Pesisir Pantai}

Penelitian terhadap 14 aksesi jarak pagar di daerah pesisir pantai ini bertujuan untuk mengetahui aksesi yang memiliki pertumbuhan terbaik berdasarkan 15 karakter pertumbuhan. Namun, untuk penapisan terhadap aksesi yang toleran di daerah pesisir pantai dilakukan berdasarkan delapan karakter terpilih yang menunjukkan adanya perbedaan nyata dengan uji 
DMRT pada taraf 5\%. Karakter-karakter tersebut terdiri atas tinggi tanaman, jumlah cabang primer, jumlah cabang produktif, jumlah bunga betina/ hermaprodit per malai, jumlai malai per tanaman, jumlah buah per malai, jumlah buah per tanaman, dan bobot biji kering per tanaman (Tabel 7). Berdasarkan nilai karakter tertinggi (8 karakter; vegetatif dan generatif) dapat digolongkan menjadi dua kelompok. Kelompok aksesi yang tergolong baik ditanam di daerah pesisir pantai nilai karakter tertingginya 7-8, sedangkan kelompok aksesi yang tergolong tidak baik adalah $<7$, seperti yang terlihat pada Tabel 7 .

Hasil penapisan menunjukkan bahwa ada dua aksesi yang tergolong baik ditanam di daerah pesisir pantai, yaitu Bogor 80-11-5 dan IP-2P 110-1-4, aksesi yang tergolong tidak baik yaitu Bontomaramu 1-1, Medan, Pinrang, Sukabumi, Bengkulu 3, Gunung Tambora, Lombok 59-1-2, Aceh Besar, Bima dan Bone.

\section{KESIMPULAN}

Hasil penapisan berdasarkan karakter pertumbuhan fase vegetatif dan generatif menunjukkan bahwa ada dua aksesi yang tergolong baik dikembangkan di daerah pesisir pantai adalah Bogor 80-11-5 dan IP-2P 110-1-4, sedangkan aksesi yang tergolong tidak baik adalah Bontomaramu 1-1, Medan dan Pinrang, Sukabumi, Bengkulu 3, Gunung Tambora, Lombok 59-1-2, Aceh Besar, Bima, Bone, Dompu dan Luwu Utara.

\section{UCAPAN TERIMA KASIH}

Penulis menyampaikan terima kasih kepada SBRC (Surfactant and Bioenergy Research Center) IPB yang telah mendanai penelitian.

\section{DAFTAR PUSTAKA}

Asbani, N., D. Winarno. 2009. Bioekologi penyerbukan dan pembuahan pada jarak pagar andromonoecious. Jurnal Agrivita 31 (1) : 12 -18 .

Badan Pusat Statistik. 2010. Penduduk Indonesia Menurut Provinsi 1971, 1980, 1990, 1995, 2000 dan 2010. http://www.bps.go.id. [13 Februari 2011].

Ferry, Y.,D.Pranowo, M.Herman.Pengaruh setektanam langsung terhadap pertumbuhan dan produksi jarak pagar (Jatropha curcas L.). Prosiding Lokakarya II Status Teknologi Tanaman Jarak Pagar (Jatropha curcas L.). Badan Penelitian dan Pengembangan Pertanian Pusat Penelitian dan Pengembangan Perkebunan. Bogor. $2: 27$ -29 .

Hambali, E., A. Suryani, Dadang, Hariyadi, H. Hanafie, I.K. Reksowardojo, M. Rivai, M. Ihsanur, P. Suryadarma, S. Tjitrosemito, T. H. Soerawidjaja, T. Prawitasari, T. Prakoso, W. Purnama. 2006. Jarak Pagar Tanaman Biodiesel. Penebar Swadaya. Depok.

Hambali, E., S. Mujdalipah, A.H. Tambunan, A.W. Pattiwiri, R. Hendroko. 2007. Teknologi Bioenergi. PT Agromedia Pustaka. Jakarta.

Hamdi, A. H. 2007. Implementasi Kebijakan Pengembangan Jarak Pagar Sebagai Sumber BBN. Prosiding Lokakarya II Status Teknologi Tanaman Jarak Pagar (Jatropha curcas L.). Badan Penelitian dan Pengembangan Pertanian Pusat Penelitian dan Pengembangan Perkebunan. Bogor. 2: 1 - 6 .

Hariyadi. 2005. Sistem Budidaya pada Tanaman Jarak Pagar (Jatropha curcas Linn). Prosiding Seminar Nasional Pengembangan Jarak Pagar (Jatropha curcas Linn) untuk Biodiesel dan Minyak Bakar. Pusat Penelitian Surfaktan dan Bioenergi Lembaga Penelitian dan Pemberdayaan Masyarakat Institut Pertanian Bogor. Bogor. $162-173$.

Hartati, R.R., A. Setiawan, B. Heliyanto, Sudarsono. 2009. Keragaan morfologi dan hasil 60 individu jarak pagar (Jatropha Curcas L.) terpilih di Kebun Percobaan Pakuwon Sukabumi. Jurnal Littri 15(4) : 152 - 161.

Hasnam. 2007. Status Perbaikan dan Penyediaan Bahan Tanaman Jarak Pagar (Jatropha curcas L.). Prosiding Lokakarya II Status Teknologi Tanaman Jarak Pagar (Jatropha curcas L.). Badan Penelitian dan Pengembangan Pertanian Pusat Penelitian dan Pengembangan Perkebunan. Bogor. $2: 7$ - 16.

Misnen. 2010. Penapisan Genotipe Jarak Pagar (Jatropha curcas L.) untuk Toleransi terhadap Kekeringan. Tesis. Sekolah Pascasarjana. Institut Pertanian Bogor. Bogor.

Nisya, F.N. 2010. Analisis keragaman genetik jarak pagar (jatropha curcas 1.) berdasarkan karakter morfologi, agronomi, dan marka RAPD. Tesis. Sekolah Pascasarjana. Institut Pertanian Bogor. Bogor.

Parwata, I.G.M.A., D. Indradewa, P. Yudono, B.D. 
Kertonegoro. 2010. Pengelompokan genotipe jarak pagar berdasarkan ketahanannya terhadap kekeringan pada fase pembibitan di lahan pasir pantai. Jurnal Agronomi Indonesia 38 (2) : 156 -162 .

Pranowo, D. M. Herman, Y. Ferry. 2007. Pengaruh Pengolahan Tanah dan Pemupukan terhadap Pertumbuhan dan Produksi Awal Jarak Pagar. Prosiding Lokakarya II Status Teknologi Tanaman Jarak Pagar (Jatropha curcas L.). Badan Penelitian dan Pengembangan Pertanian Pusat Penelitian dan Pengembangan Perkebunan. Bogor. $2: 23$ - 26.

Santoso, B.B., B.S. Purwoko. 2008. Pertumbuhan bibit tanaman Jarak Pagar (Jatropha curcas L.) pada berbagai kedalaman dan posisi tanam benih. Buletin Agronomi 36 (1) : 70 - 77.

Satyarini, T.B. 2009. Analisis usaha tani cabai di lahan pantai(Studi kasus di Pantai pandan simo, Bantul, DIY). Seminar Nasional Peningkatan Daya Saing Agribisnis Berorientasi Kesejahteraan Petani.
Pusat Analisis Sosial Ekonomi Dan Kebijakan Pertanian Badan Penelitian dan Pengembangan Pertanian Departemen Pertanian 2009. Bogor. 1 -12 .

Sumanto. 2006. Pengaruh Media dan Waktu Panen Buah Terhadap Pertumbuhan Bibit Jarak Pagar (Jatropha curcas L.). Prosiding Lokakarya II Status Teknologi Tanaman Jarak Pagar (Jatropha curcas L.). Badan Penelitian dan Pengembangan Pertanian Pusat Penelitian dan Pengembangan Perkebunan. Bogor. 2 : $104-106$.

Triyogo, A., Sumardi dan D.A. Winastuti. 2009. Pengaruh jenis mulsa terhadap kapasitas penambatan spesifik nitrogen cemara udang (Casuarina equisetifolia Linn.) pada kondisi tempat tumbuh yang berbeda. Jurnal Agronomi Indonesia 37 (1) : $71-77$.

Utomo. 2009. Penentuan Periode Reseptif Dan Masak Fisiologis Jarak Pagar (Jatropha Curcas L.). http://penentuanperiodereseptif/pdf/BBP2TP. [12 Januari 2012]. 